\title{
Control of peroxyoxalate chemiluminescence by nitrogen-containing ligand quenching: turning off and on by ligand-metal ion host-guest interactions
}

Takayuki Maruyama, Yasuyuki Fujie, Noriyuki Oya, Eisuke Hosaka, Aki Kanazawa, Daisuke Tanaka, Yoshiyuki Hattori, Jiro Motoyoshiya*

Division of Chemistry and Materials, Faculty of Textile Science and Technology, Shinshu University, Ueda, Nagano 386-8567, Japan

* Corresponding author. Tel: +8126821 5402; Fax: +81268215391.

E-mail address: jmotoyo@shinshu-u.ac.jp (J. Motoyoshiya)

Abstract:

The control of peroxyoxalate chemiluminescence (PO-CL) by the coordination of nitrogen-containing ligands and metal cations was investigated. Turning the CL off and on was done by PO-CL using 15-monoazacrown-5-tethered anthracene and alkali metal ions. CL quenching and regeneration was also observed in the separated molecular system of 15-monoazacrown-5 and the fluorophores. CL quenching by a number of ligands bearing dipicolylamino groups was evaluated by these PO-CL reactions and found to be closely related to their oxidation potentials, which is dependent on the Weller rate law for electron exchange and this provides strong support for the existence of the CIEEL PO-CL process. When $\mathrm{Zn}^{2+}$ or $\mathrm{Cu}^{2+}$ are added to the PO-CL system quenched by the ligand, $N$-[2-(2,2'-dipicolylamino)ethyl]aniline, CL was turned on because the electron donating ability of the ligands was modulated. This was controlled by the coordination of the studied metal ions and, therefore, this system results in CL because of host-guest interactions.

Keywords: peroxyoxalate chemiluminescence, quenching, CIEEL, ligand, dipicolylamino group

\section{Introduction}

Chemiluminescence (CL) is becoming important in many applications beyond chemical analyses, such as in biological diagnostics, because an electric light source is not required to decrease the background noise, which results in the detection of light only from the fluorescent target species. ${ }^{1}$ Of all the CL reactions, peroxyoxalate chemiluminescence (PO-CL) that is 
generated from the reactions of active oxalates bearing phenol moieties that contain electron withdrawing groups such as bis(2,4,6-tricholorophenyl) oxalate (TCPO) or bis(2,4-dinitrophenyl) oxalate (DNPO) and alkaline hydrogen peroxide in the presence of various fluorophores is the most effective (Scheme 1). An enormous amount of effort has been put into mechanistic studies ${ }^{2}$ and into analytical applications. ${ }^{3}$

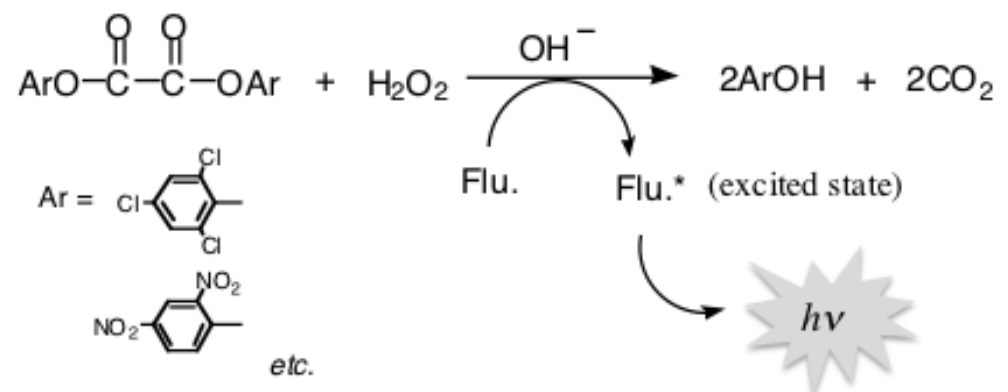

Scheme 1. Peroxyoxalate chemiluminescence (PO-CL) reaction.

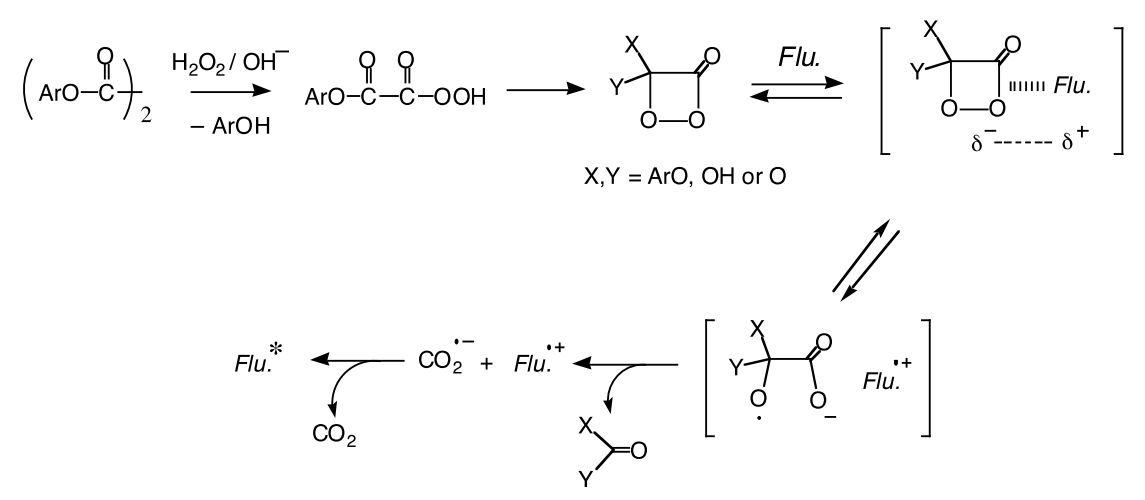

Scheme 2. A plausible CIEEL process during PO-CL.

A chemically initiated electron exchange luminescence (CIEEL) process has been suggested to be a pluasible explanation for the chemiexcitation pathway during PO-CL (Scheme 2). ${ }^{4}$ In this process the electron exchange between high energy intermediates (acceptors), 1,2-dioxetanones or 1,2-dioxetanedione, and fluorophores (donors) is a crucial step. Based on this convincing mechanism we hypothesize that if additives control the CIEEL process by an electronic interaction the CL might turn off and on under suitable conditions. To turn the CL off, CL quenching should be dependent on the electron donating ability of the organic additives and this electron donor additive might interrupt the CIEEL process and disrupt the electron exchange between the high energy intermediate and a fluorophore. Therefore, an electron donating additive and a fluorophore would compete during their interaction with the dioxetanones. The additive would, therefore, behave as a CL quencher. When the additive is a nitrogen-containing ligand, the complexation of a suitable metal ion to the ligand can control its 
electron donating ability and the metal ion will become important in switching the CL on. If this process operates in an intermolecular manner there is a possibility that a good choice of a combination of additives will enable the visualization of various molecular interactions by the CL technique, as shown in Scheme 3.

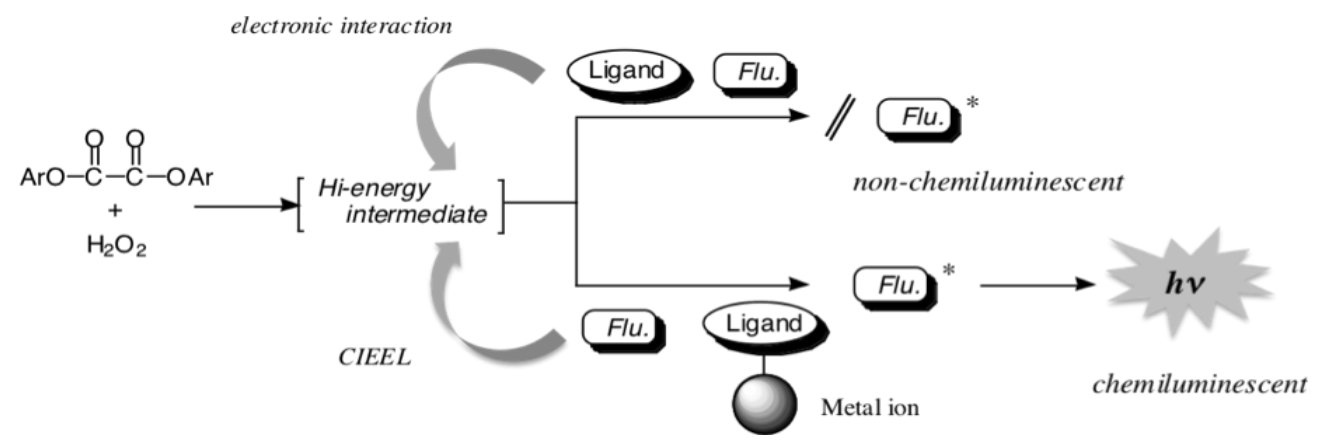

Scheme 3. Concept of CL detection during host-guest interactions.

In this paper, CL control by a host-guest interaction during PO-CL reactions was investigated using several nitrogen-containing ligands. Efforts were directed toward finding a relationship between the electronic effect of the ligands and CL quenching during the CIEEL process. This was applied to the CL detection of the host-guest interaction between the ligands and the metal ions. This system resembles a displacement indicator assay, ${ }^{5}$ which is a fluorescence detection method in which analyte binding leads to indicator displacement to yield optical signal modulation. However, this is the first time that such a noncovalent system has been used in a CL reaction.

\section{Results and discussion}

\subsection{CL control with azacrown ethers in an intra- and intermolecular fashion}

15-monoazacrown-5-tethered anthracene (1) is a well-known fluorescent compound ${ }^{6}$ capable of changing its fluorescence intensity upon chelation by suitable metal ions and this fluorescence modulation is due to the control of fluorescence quenching by intramolecular photoinduced electron transfer (PET). When this compound is used as a fluorophore in PO-CL the $\mathrm{CL}$ is also expected to be controlled by the interaction with metal ions. 


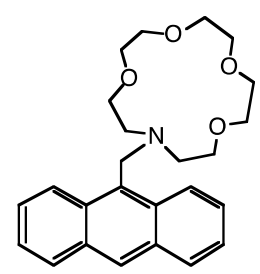

1

Before the application of $\mathbf{1}$ to a chemiluminescence reaction, its fluorescence behavior upon metal ion complexation was explored. The ionophore 15-monoazacrown-5 can incorporate various alkali- and alkaline earth metal ions and among them sodium and calcium cations are most effective in increasing the fluorescence intensity of 15-monoazacrown-5-tethered fluorescent molecules by interrupting PET fluorescence quenching. ${ }^{7}$ The fluorescence spectra of 1 were measured under various $\mathrm{Na}^{+}$concentrations because the interaction of $\mathbf{1}$ and $\mathrm{Na}^{+}$has not been well documented. As shown in Fig. 1, the fluorescence intensity increased markedly as the $\mathrm{Na}^{+}$concentration increased despite the required large excess of $\mathrm{Na}^{+}$, which led us to apply this event to the chemiluminescence system.

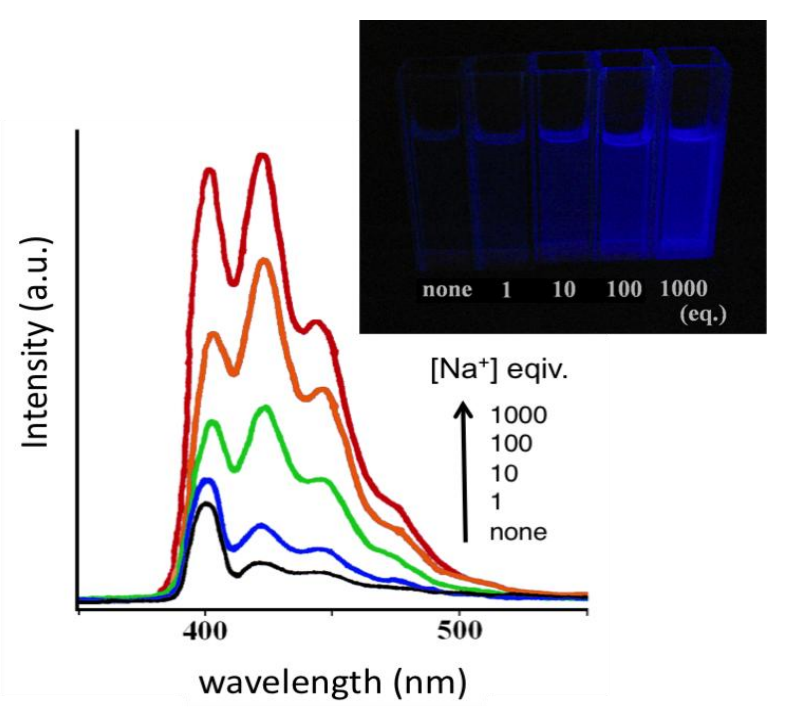

Fig. 1. Fluorescence spectra of $\mathbf{1}$ as a function of $\left[\mathrm{NaClO}_{4}\right]$.

$[\mathbf{1}]=1.0 \times 10^{-4} \mathrm{M}$ in THF.

Using 1 as a fluoroionophore the CL reaction was carried out using several reagents including bis(4-chlorophenyl) oxalate (4-CPO), hydrogen peroxide and tetrabutylammonium hydroxide (TBAH) as a metal free base. The reaction without any metal cation in aqueous THF gave a weak CL emission, as expected from the fluorescence spectrum shown in Fig. 1. In contrast, the addition of $\mathrm{NaClO}_{4}$ increased the CL quantum yield $\left(\Phi_{\mathrm{CL}}\right) 10$ times compared to the system without $\mathrm{Na}^{+}$. Among the alkali metal ions tested in this study, $\mathrm{Na}^{+}$was the most effective in 
increasing the $\Phi_{\mathrm{CL}}$, as shown in Fig. 2, which is based on the advantageous incorporation of $\mathrm{Na}^{+}$ into the azacrown cavity. ${ }^{7}$

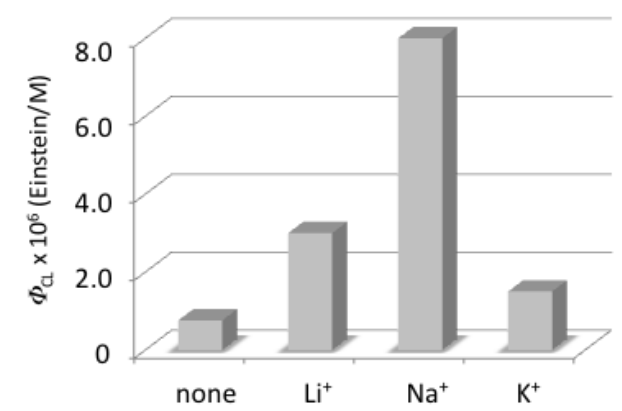

Fig. 2. PO-CL for compound 1 and the alkali metal ions. $1\left(7.5 \times 10^{-4} \mathrm{M}\right)$, 4-CPO $\left(7.5 \times 10^{-5} \mathrm{M}\right)$, $\mathrm{LiClO}_{4}, \mathrm{NaClO}_{4}$ and $\mathrm{KClO}_{4}\left(7.5 \times 10^{-3} \mathrm{M}\right), \mathrm{H}_{2} \mathrm{O}_{2}$ $\left(7.5 \times 10^{-3} \mathrm{M}\right)$ and TBAH $\left(7.5 \times 10^{-4} \mathrm{M}\right)$ in $\mathrm{H}_{2} \mathrm{O} / \mathrm{THF}$ $(1: 3)$.

It is noteworthy that turning the CL off or on could also be done in an intermolecular fashion using molecules where a fluorophore and an ionophore are not covalently linked such as free anthracene and 15-monoazacrown-5. Turning the CL off was done by adding 15-monoazacrown-5 to the CL system containing 4-CPO, TBAH, hydrogen peroxide and anthracene as a fluorophore. The $\mathrm{CL}$ intensity decreased with an increase in the 15-monoazacrown-5 concentration and it finally disappeared when 50 equivalents of azacrown ether was added to the oxalate (Fig. 3), and hence 15-monoazacrown-5 acted as a CL quencher during this PO-CL reaction. Upon the addition of $\mathrm{NaClO}_{4}$ to the non-luminescent PO-CL system that was quenched by the azacrown, $\Phi_{\mathrm{CL}}$ recovered to a value 2.3 times higher than the system without $\mathrm{Na}^{+}$while a $\Phi_{\mathrm{CL}}$ value 100 times higher was obtained when coumarin-7 was used as a fluorophore (Fig.3, inset). During CL quenching an electronic interaction takes place between the ligands and the high energy intermediates rather than fluorescence quenching between the ligands and the fluorophores by intermolecular PET because the solutions containing the fluorophores and the azacrown do not give significant fluorescence quenching even when using 100 times more azacrown at which the CL emission from the PO-CL reaction would be completely quenched. Thus, in this PO-CL reaction the azacrown is an electron donor to the high energy peroxyoxalate intermediates and it does not donate electrons to the electronically excited fluorophores. The high energy intermediates such as dioxetanones act as electron acceptors to inhibit the chemiexcitation of the fluorophores resulting in CL quenching. This process involves the CL turning off or on, and implies that the CL can be controlled by the host-guest interaction between the various ligands and metal ions. 


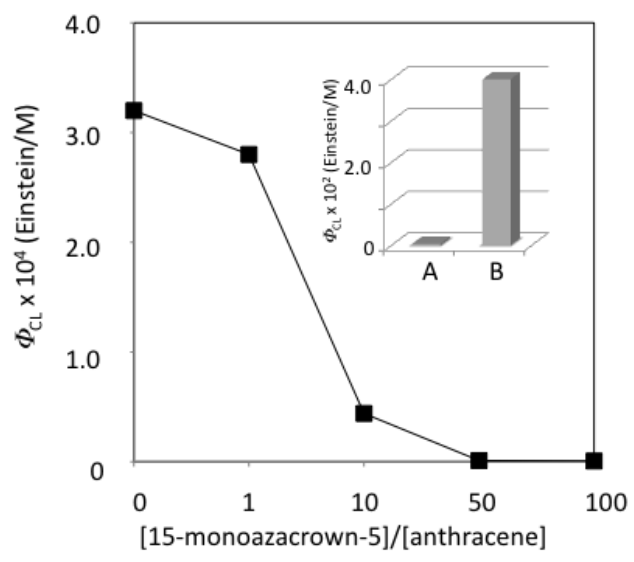

Fig. 3. PO-CL quenching by 15 -monoazacrown-5 and $\mathrm{CL}$ recovery by the addition of coumarin- 7 and $\mathrm{Na}^{+}$(inset).

4-CPO $\left(1.0 \times 10^{-4} \mathrm{M}\right)$, anthracene $\left(1.0 \times 10^{-3} \mathrm{M}\right)$, 5-monoazacrown-15(0-1.0x $\left.10^{-1} \mathrm{M}\right), \mathrm{H}_{2} \mathrm{O}_{2}\left(1.2 \times 10^{-1} \mathrm{M}\right)$, $\operatorname{TBAH}\left(1.0 \times 10^{-3} \mathrm{M}\right)$ in $\mathrm{H}_{2} \mathrm{O} / \mathrm{THF}(1: 3)$. Inset: $\mathrm{A} ; 4-\mathrm{CPO}\left(0.75 \times 10^{-4} \mathrm{M}\right), \mathrm{H}_{2} \mathrm{O}_{2}\left(0.25 \times 10^{-2} \mathrm{M}\right)$, TBAH $\left(0.25 \times 10^{-4} \mathrm{M}\right), 15$-monoazacrown-5 $\left(0.75 \times 10^{-3} \mathrm{M}\right)$, coumarin- $7\left(0.75 \times 10^{-4} \mathrm{M}\right)$. B; addition of $\mathrm{NaClO}_{4}\left(0.75 \times 10^{-1} \mathrm{M}\right)$.

\subsection{Preparation and oxidation potentials of the ligands}

Dipicolylamino groups are useful as chelators in fluorescence chemosensors ${ }^{8}$ for the detection of biologically important metal ions, because of their strong electron donating ability, as well as their strong coordination of particular metal ions with excellent selectivity. We applied this functionality containing multiple nitrogen atoms to the PO-CL system and its intensity was controlled by the metal ion-ligand interaction (vide infra). The ligands (2-4) shown in Fig. 4 were prepared by a modification of the established method $^{8 \mathrm{c}-\mathrm{d}, 9}$ using the reactions of 2-(chloromethyl)pyridine and the corresponding amines. To investigate the effect of these ligands on CL quenching their oxidation potentials (Eox) were measured by cyclic voltammetry. As shown in Table 1, the Eox's of the ligands are dependent on their electronic nature as modulated by the attached substituents for ligands $\mathbf{2 a - c}$ and 3a-c. The electron donating substituents increase the electron releasing ability, which leads to a lower Eox. Ligand $\mathbf{4}$ has the highest Eox among all the ligands probably because of its radical cation that is generated after the release of an electron, which causes it to be less stable as a result of the lack of a directly linked aromatic ring on the nitrogen atom. 


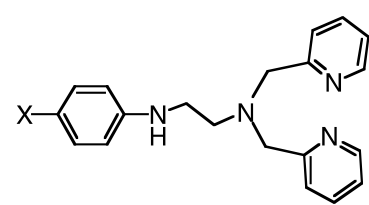

2a $X=H$

2b $\mathrm{X}=\mathrm{Cl}$

2c $X=\mathrm{OMe}$
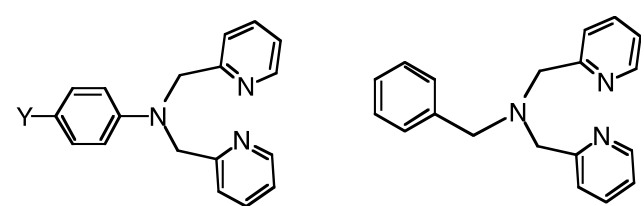

4

Fig. 4. Structures of the ligands used in this study.

Table 1.

Oxidation potentials (Eox.) of ligands 2,3, and 4

\begin{tabular}{ll}
\hline Ligand & Eox. $(\mathrm{V})^{a}$ \\
\hline & \\
$\mathbf{2 a}$ & 0.66 \\
$\mathbf{2 b}$ & 0.70 \\
$\mathbf{2 c}$ & 0.45 \\
$\mathbf{3 a}$ & 0.35 \\
$\mathbf{3 b}$ & 0.87 \\
$\mathbf{3 c}$ & 0.23 \\
$\mathbf{4}$ & 0.93 \\
\hline
\end{tabular}

\footnotetext{
${ }^{a}$ The measurements were carried out in $\mathrm{THF} / \mathrm{H}_{2} \mathrm{O}(1: 1)$. The ligand concentration was $0.01 \mathrm{M}$ and the electrolyte was $\mathrm{Bu}_{4} \mathrm{NClO}_{4}$. Platinum working electrode, $\mathrm{Ag} / \mathrm{AgCl}$ reference electrode. Scan rate of $10 \mathrm{mVs}^{-1}$.
}

\subsection{CL quenching by the ligands containing dipicolyl groups}

To investigate the role of the series of ligands described above as CL quenchers systematically, the effect of ligand 2a on PO-CL quenching was studied. PO-CL reactions that included TCPO as an oxalate, hydrogen peroxide, $\mathrm{Na}_{2} \mathrm{CO}_{3}$, four kinds of fluorophores and $\mathbf{2 a}$ at various concentrations were carried out. As shown in Fig. 4, the CL intensity in the presence of fluorophores such as 9, 10-diphenylanthracene (DPA), perylene, rubrene, and coumarin-7 gradually decreased along with an increase in the amount of 2a. The PO-CL intensity is known to depend on the electronic property as well as the fluorescent properties of the fluorophores. ${ }^{21,4}$, ${ }^{10}$ Therefore, the CL intensity decayed in different ways for each fluorophore, as shown Fig. 5. The CL was almost completely inhibited when a large excess of $\mathbf{2 a}$ was added in all cases. It is important to note that $\mathbf{2 a}$ might be superior to the fluorophores as an electron donor because of its much lower oxidation potentials compared to all the fluorophores used here $(1.24,0.96,0.94$, 
1.11 (V) for DPA, perylene, rubrene, and coumarin-7, respectively).

For a systematic CL quenching study of the CIEEL process, a series of ligands (2a-c, 3a-c, and 4) were employed for the PO-CL reactions in the presence of 4-CPO and perylene as the common oxalate and fluorophore, respectively. Of the seven ligands investigated $\mathbf{2 a - c}, \mathbf{3 a}$ and 3c quenched the CL but $\mathbf{3 b}$ and $\mathbf{4}$ were much less effective (Fig. 6). If the observed CL quenching involves an electronic interaction and the ligands compete with the fluorophores during the CIEEL process the effect of the ligands on CL quenching should be closely related to their Eox's. The CL ligand quenching trend agrees with this relation because $\mathbf{3 b}$ and $\mathbf{4}$, with a higher Eox, are inferior to the other ligands with a lower Eox during CL quenching.

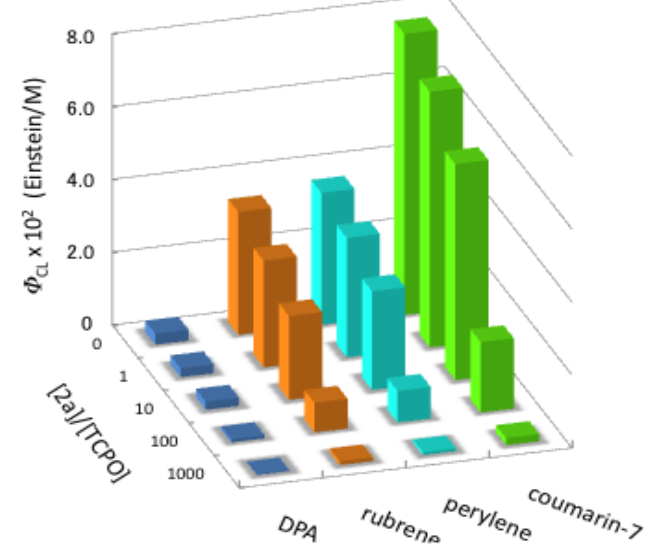

Fig. 5. CL quenching in the presence of 2 a during PO-CL using various fluorophores. TCPO $\left(0.75 \times 10^{-5} \mathrm{M}\right)$, the fluorophore $\left(0.75 \times 10^{-4} \mathrm{M}\right), \mathrm{H}_{2} \mathrm{O}_{2}\left(0.25 \times 10^{-2} \mathrm{M}\right)$ and $\mathrm{Na}_{2} \mathrm{CO}_{3}\left(1.25 \times 10^{-4} \mathrm{M}\right)$ in $\mathrm{THF} / \mathrm{H}_{2} \mathrm{O}(3: 1)$ were used.

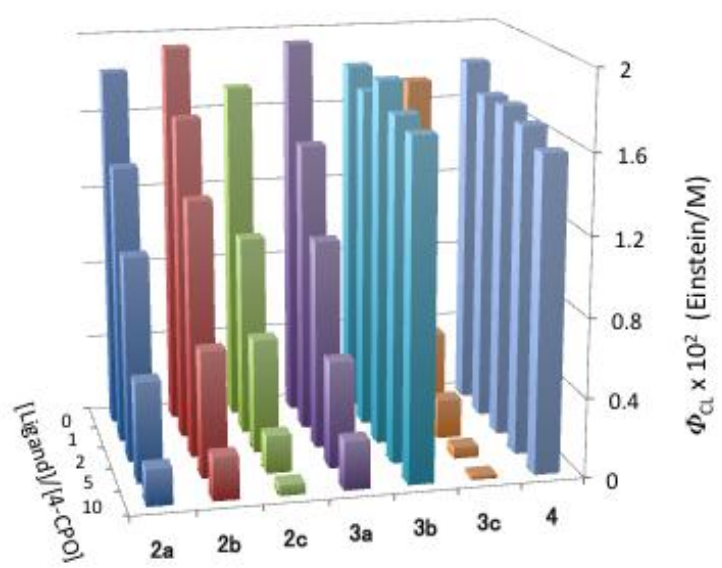

Fig. 6. Ratio of $\Phi_{\mathrm{CL}}$ decrease because of the addition of ligands $\mathbf{2 a}, \mathbf{2 b}, \mathbf{2 c}, \mathbf{3 a}$ and $\mathbf{3 c}$ during PO-CL. 4-CPO $\left(0.75 \times 10^{-5} \mathrm{M}\right)$, perylene $\left(0.75 \times 10^{-4} \mathrm{M}\right), \mathrm{H}_{2} \mathrm{O}_{2}$ $\left(0.25 \times 10^{-2} \mathrm{M}\right)$ and $\mathrm{Bu}_{4} \mathrm{NOH}\left(1.25 \times 10^{-4} \mathrm{M}\right)$ in $\mathrm{THF} / \mathrm{H}_{2} \mathrm{O}(1: 1)$ were used.

During the enhanced (indirect) CL, with PO-CL being typical, the high-energy intermediates interact with the fluorophores to generate excited fluorophores resulting in CL emission from 
their fluorescence process. The kinetics of this process have been well established. ${ }^{2 \mathrm{a}}$ The double reciprocals of $\Phi_{\mathrm{CL}}$ and the fluorophore concentration [F] are correlated by a single straight line. On the other hand, the Stern-Volmer equation has been applied to metal ion-induced CL quenching in a few cases with regards to their quantification. ${ }^{11}$ Independently, we applied the kinetics of the enhanced CL to the present ligand-induced CL quenching by exploiting the elementary reaction of the CL quenching process involving the interaction between the high energy intermediate and the ligands. The obtained equation shown below resembles the Stern-Volmer equation, and it has a linear relationship between the double reciprocals of $\Phi_{\mathrm{CL}}$ and $[\mathrm{F}]$,

$$
1 / \Phi_{\mathrm{CL}}=1 / \Phi_{\mathrm{r}} \Phi_{\mathrm{F}}\left(1+k_{\mathrm{Q}}[\mathrm{L}] / k_{\mathrm{ss}}[\mathrm{F}]\right)
$$

where $\Phi_{\mathrm{r}}$ and $\Phi_{\mathrm{F}}$ are the reaction yield and the fluorescence quantum yield of the fluorophore, respectively. $k_{\mathrm{ss}}$ is the rate constant for energy transfer from the high energy intermediate to the fluorophores and $k_{\mathrm{Q}}$ is a conditional CL quenching constant that is estimated as a measure of the CL quenching ability of the ligands. This eqation indicates that the ligands behave as quenchers and a plot of the ligand concentration [L] vs. the reciprocal $\Phi_{\mathrm{CL}}$ should give a straight line when using a constant $[\mathrm{F}]$. In addition, the slope $k_{\mathrm{Q}} / \Phi_{\mathrm{r}} \Phi_{\mathrm{F}} k_{\mathrm{SS}}[\mathrm{F}]$ provides a relative $k_{\mathrm{Q}}$ for each ligand. Using various concentrations of $\mathbf{2 a - c}$ and $\mathbf{3 c}$ and by keeping [F] constant the $\Phi_{\mathrm{CL}}$ 's of perylene-enhanced PO-CL from the reaction of 4-CPO and alkaline hydrogen peroxide were determined. As shown in Fig. 7 , the plots of $[\mathrm{L}]$ and $1 / \Phi_{\mathrm{CL}}$

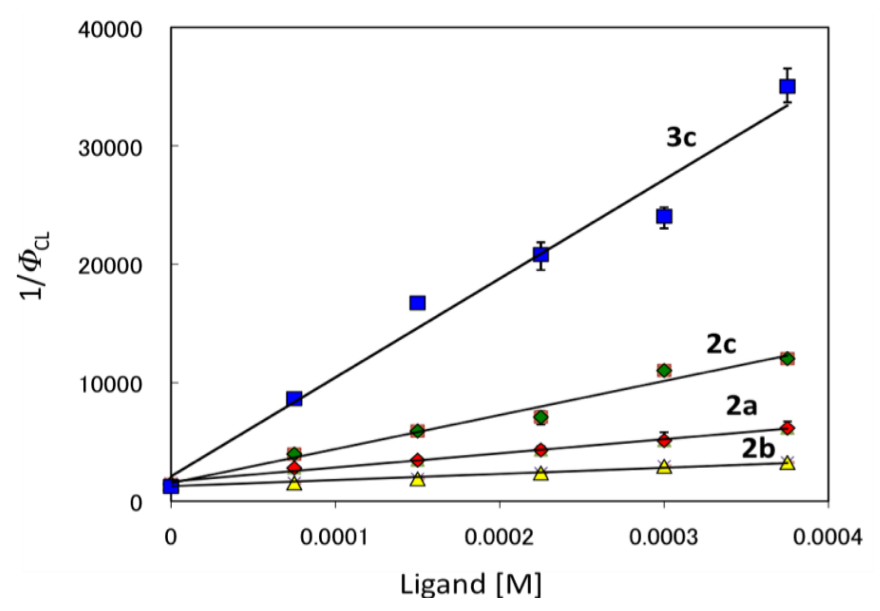

Fig. 7. Plot of $\mathrm{CL}$ quenching according to equation (1).

4-CPO $\left(0.75 \times 10^{-5} \mathrm{M}\right)$, perylene $\left(0.75 \times 10^{-4} \mathrm{M}\right), \mathrm{H}_{2} \mathrm{O}_{2}\left(0.25 \times 10^{-2} \mathrm{M}\right)$ and $\mathrm{Na}_{2} \mathrm{CO}_{3}\left(5.0 \times 10^{-5} \mathrm{M}\right)$ in $\mathrm{THF} / \mathrm{H}_{2} \mathrm{O}(1: 1)$ were used. $\mathrm{R}^{2}=0.975$ for $\mathbf{3 c}, 0.979$ for $\mathbf{2 c}, 0.992$ for $\mathbf{2 a}$ and 0.962 for $\mathbf{2 b}$. 


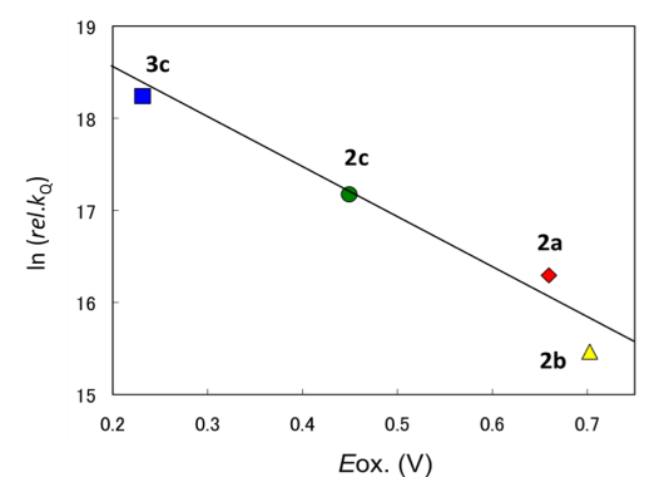

Fig. 8. Plot of $\ln \left(\right.$ rel. $\left.k_{\mathrm{Q}}\right)$ against the Eox of the ligands.

form straight lines, which implies that the ligands interact with the high energy intermediates in a bimolecular manner and behave as CL quenchers during enhanced PO-CL. It is noteworthy that the linear relationship between $\ln \left(\right.$ rel. $\left.k_{\mathrm{Q}}\right)$ and the Eox of the ligands is consistent with the Weller rate law ${ }^{12}$ for electron exchange (Fig. 8), except for the weakly fluorescent ligand 3a and the ligands $\mathbf{3 b}$ and $\mathbf{4}$, which were not effective CL quenchers. These results provide evidence for the involvement of an electron exchange process, the CIEEL process, during PO-CL from a different point of view as has been reported previously in the literature. ${ }^{4}$

\subsection{Turning CL on by the interaction between ligands and metal cations}

Because of the strong chelating effect of dipicolyl groups, ${ }^{13}$ ligands $\mathbf{2 a - c}$ coordinate to suitable metal ions to modulate their electron donating ability, which affects the modulation of the CL intensity of PO-CL. Since $\mathrm{Zn}^{2+}$ is known to coordinate with the 2-(dipicolylamino)ethylamino ligand and this favorable complexiation has been widely used for fluorescent chemosensors ${ }^{14}$ the Zn-salt was employed to turn CL on by its interaction with 2a-c. As described before, these ligands quench the CL from the PO-CL reactions in the presence of various fluorophores (Fig. 6 for the TCPO-PO-CL reaction). The effect of $\mathrm{Zn}^{2+}$ on CL regeneration was examined using various $\mathrm{Zn}^{2+}$ concentrations. In the rubrene-enhanced TCPO-PO-CL reaction, $\Phi_{\mathrm{CL}}$ increased sharply at an equivalent concentration between $\mathbf{2 a}$ and $\mathrm{Zn}^{2+}$ and at this point the maximum CL was observed. The $\Phi_{\mathrm{CL}}$ recovered to $20 \%$ of its initial value compared to the system without $2 \mathbf{a}$ and $\mathrm{Zn}^{2+}$. The use of perylene as a fluorophore instead of rubrene led to the regeneration of CL at up to $56 \%, 44 \%$, and $40 \%$ at the maximum points by the coordination of $\mathbf{2 a}, \mathbf{2 b}$ and $\mathbf{2 c}$ with $\mathrm{Zn}^{2+}$ in 1:1 ratios (Fig. 9). However, the much higher concentration of the Zn-salt decreased the CL intensity probably because of a change in the $\mathrm{pH}$ of the solutions, which unfortunately restricts the application of this system to the quantification of $\mathrm{Zn}^{2+}$. On the other hand, the effect of highly fluorescent coumarin-7 in turning the CL on was 
studied using a lower concentration of $2 \mathbf{a}\left(10^{-4} \mathrm{M}\right)$, and $54 \% \mathrm{CL}$ recovery was obtained. Therefore, the metal ion-ligand complexation between these additives can be determined at $10^{-4}$ $\mathrm{M}$ by this CL system when suitable conditions are used. Attempts to find the host-guest interaction between $\mathbf{2 a}$ and other metal ions were also made in the presence of $\mathrm{Li}^{+}, \mathrm{Ca}^{2+}, \mathrm{Mn}^{2+}$, $\mathrm{Co}^{2+}$ and $\mathrm{Cu}^{2+}$ and we found that $\mathrm{Cu}^{2+}$ with an ionic radius similar to $\mathrm{Zn}^{2+}$ also responded to $2 \mathbf{a}$ (Fig. 10). Here, we show only a few examples of CL regeneration by host-guest interactions and these results show that host-guest interactions can be determined using CL, as shown in Scheme 3.

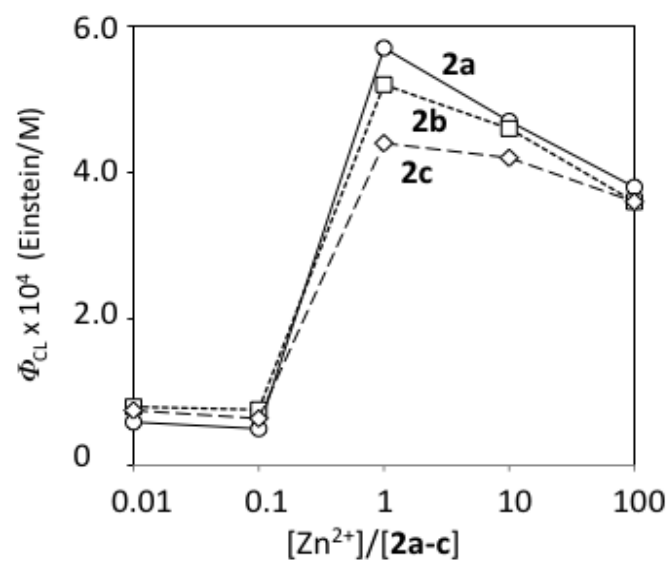

Fig. 9. Turning CL on by the interaction between $2 \mathbf{a}-\mathbf{c}$ and $\mathrm{Zn}^{2+}$. TCPO $\left(1.0 \times 10^{-4} \mathrm{M}\right), \mathrm{Na}_{2} \mathrm{CO}_{3}\left(1.0 \times 10^{-4} \mathrm{M}\right), \mathrm{H}_{2} \mathrm{O}_{2}\left(1.2 \times 10^{-2} \mathrm{M}\right)$, Perylene $\left(1.0 \times 10^{-4} \mathrm{M}\right)$ and ligands $\left(1.0 \times 10^{-3} \mathrm{M}\right)$ were used.

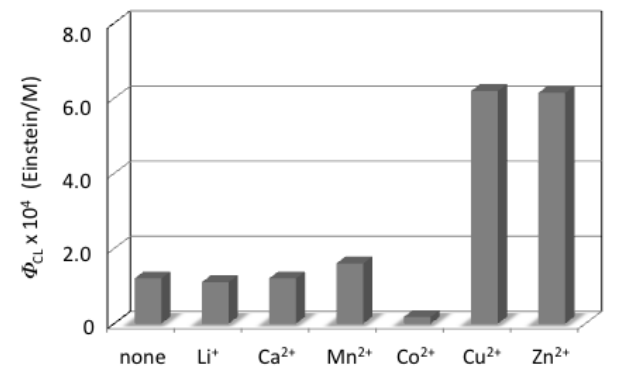

Fig. 10. Metal ion selective turning on of CL. TCPO $\left(0.75 \times 10^{-5} \mathrm{M}\right)$, perylene $\left(0.75 \times 10^{-4} \mathrm{M}\right)$, 2a $\left(0.75 \times 10^{-3} \mathrm{M}\right)$, metal ion $\left(0.75 \times 10^{-3} \mathrm{M}, \mathrm{LiClO}_{4}\right.$, $\left.\mathrm{Ca}\left(\mathrm{ClO}_{4}\right)_{2}, \mathrm{MnSO}_{4}, \mathrm{CoSO}_{4}, \mathrm{CuSO}_{4}, \mathrm{ZnSO}_{4}\right)$, $\mathrm{H}_{2} \mathrm{O}_{2}\left(0.25 \times 10^{-2} \mathrm{M}\right)$ and $\mathrm{Na}_{2} \mathrm{CO}_{3}\left(0.25 \times 10^{-4} \mathrm{M}\right)$ in $\mathrm{THF} / \mathrm{H}_{2} \mathrm{O}(1: 1)$ were used.

\section{Conclusions}


A new aspect of PO-CL reactions as a result of the combination of various fluorophores, ligands bearing dipicolylamino groups and metal ions is demonstrated. The ligands act as CL quenchers by an electronic effect, but the CL turns on in the presence of suitable metal ions because of the control of the electronic effect by the complexation of metal ions with the ligands. Strong evidence for the CIEEL process was also found based on the relationship between the CL quenching and the oxidation potentials of the ligands. With a good choice of ligands and fluorophores various combinations are possible as long as well designed electron donating ligands that are suitable for target molecules are available, and an investigation is currently underway in our laboratory.

\section{Experimental}

\subsection{General}

Melting points were determined using a hot stage microscope apparatus and were uncorrected. ${ }^{1} \mathrm{H}$ and ${ }^{13} \mathrm{C}$ NMR spectra were recorded on a FT-NMR spectrometer at $400 \mathrm{MHz}$ and $100 \mathrm{MHz}$, respectively. The chemical shifts $(\delta)$ of the ${ }^{1} \mathrm{H}$ and ${ }^{13} \mathrm{C}$ NMR spectra are reported in ppm downfield from TMS as an internal standard or from the residual solvent peak. Coupling constants $(J)$ are reported in Hz. Fluorescence quantum yields were estimated using 9,10-diphenylanthracene ( $\Phi_{\mathrm{F}}=0.91$ in benzene) as a standard. Chemiluminescence quantum yields $\left(\Phi_{\mathrm{CL}}\right)$ were measured by a photon-counting method using a Hamamatsu Photonics R464 photomultiplier connected to a photon-counting unit (C3866) and a photon-counting board M8784 according to a previously reported procedure. ${ }^{21}$ Luminol chemiluminescence was used as a standard in DMSO for the calibration of the photomultiplier tube. Compound (1) was prepared by an established method according to the literature. TCPO and 4-CPO were prepared by reacting oxalyl chloride and the corresponding phenols in the presence of triethylamine in benzene and were used after recrystallization.

\subsection{Preparation of azacrown-tethered anthracene (1) and ligands $2 \mathrm{a}-\mathrm{c}, 3 \mathrm{a}-\mathrm{c}$ and 4}

4.2.1. $N$-(9-anthylmethyl)monoaza-15-crown-5 (1). The reaction between 9-bromomethylanthracene (1.23 g, $4.6 \mathrm{mmol})$, 15-monoazacrown-5 (1.0 g, $4.6 \mathrm{mmol})$ and $\mathrm{Na}_{2} \mathrm{CO}_{3}(0.92 \mathrm{~g}, 8.7 \mathrm{mmol})$ was carried out in $\mathrm{CH}_{3} \mathrm{CN}$ by heating at $80{ }^{\circ} \mathrm{C}$ for $20 \mathrm{~h}$. After filtration and concentrating the filtrate purification was carried out by column chromatography $\left(\mathrm{SiO}_{2}\right.$, ethyl acetate as an eluant) and compound 1 was obtained $(0.58 \mathrm{~g}, 31 \%)$ as a viscous 
yellowish oil. ${ }^{1} \mathrm{H}$ NMR (400 MHz, $\left.\mathrm{CDCl}_{3}\right) \delta$ 2.91(t, 4H), 3.57-3.66(m, 16H), 4.61(s, 2H), 7.42-7.52(m, 4H), 7.98(d, 2H), 8.93(s, 1H), 8.54(d, 2H).

4.2.2. $\mathrm{N}$-(2-(2,2'-dipicolylamino)ethyl)aniline (2a). A solution of 2-bromoethylamine hydrobromide $(1.1 \mathrm{~g}, 5.4 \mathrm{mmol})$ and aniline $(3.0 \mathrm{~g}, 32 \mathrm{mmol})$ in toluene $(8 \mathrm{ml})$ was stirred for 1 day at $120{ }^{\circ} \mathrm{C}$ under an argon atmosphere and the precipitated product was collected by filtration. The salt was then treated with a $20 \%$ aqueous $\mathrm{NaOH}$ solution and extracted with dichloromethane. The organic phase was dried over anhydrous $\mathrm{Na}_{2} \mathrm{SO}_{4}$. After the $\mathrm{Na}_{2} \mathrm{SO}_{4}$ was filtered out and the solvent was distilled the crude product was further purified by column chromatography on silica gel (eluant: methanol) to afford $N$-phenylethylenediamine as a red-brown liquid. Yield: 87\% (0.64 g); ${ }^{1} \mathrm{H}$ NMR $\left(400 \mathrm{MHz}, \mathrm{CDCl}_{3}\right) \delta 1.51($ br s, 3H), $2.93(\mathrm{t}, 2 \mathrm{H}), 3.17(\mathrm{t}, 2 \mathrm{H}), 6.63(\mathrm{~d}, 2 \mathrm{H}), 6.70(\mathrm{t}, 1 \mathrm{H}), 7.17$ (t, 2H). 2-(Chloromethyl)pyridine hydrochloride (1.8 g, $11 \mathrm{mmol})$ was treated with a $20 \%$ aqueous $\mathrm{NaOH}$ solution and extracted with dichloromethane and the organic phase was dried over anhydrous $\mathrm{Na}_{2} \mathrm{SO}_{4}$. After $\mathrm{Na}_{2} \mathrm{SO}_{4}$ was filtered out and the solvent was evaporated off, a solution of 2-(chloromethyl)pyridine in benzene $(3 \mathrm{ml})$ was added to a solution of $N$-phenylethylenediamine (0.69 g, $5.1 \mathrm{mmol})$, which was prepared as described above, and triethylamine (5.1 g, $51 \mathrm{mmol})$ in benzene $(4 \mathrm{ml})$ and stirred for $17 \mathrm{~h}$ at $80{ }^{\circ} \mathrm{C}$ under an argon atmosphere. After being cooled to room temperature and the addition of diethyl ether, the inorganic by-products were removed by washing with a saturated $\mathrm{NaHCO}_{3}$ solution and with brine. The organic phase was dried over anhydrous $\mathrm{Na}_{2} \mathrm{SO}_{4}$. After the $\mathrm{Na}_{2} \mathrm{SO}_{4}$ was filtered out and the solvent was removed the crude product was purified by column chromatography on silica gel (eluant: ethyl acetate) to afford 2a as a red-brown viscous liquid. Yield: 69\% (1.1 g); ${ }^{1} \mathrm{H}$ NMR (400 MHz, $\left.\mathrm{CDCl}_{3}\right) \delta 2.86(\mathrm{t}, 2 \mathrm{H}), 3.17(\mathrm{t}, 2 \mathrm{H}), 3.88(\mathrm{~s}$, $4 \mathrm{H}), 6.58(\mathrm{~d}, 2 \mathrm{H}), 6.65(\mathrm{t}, 1 \mathrm{H}), 7.07-7.18(\mathrm{~m}, 4 \mathrm{H}), 7.41(\mathrm{~d}, 2 \mathrm{H}), 7.60(\mathrm{t}, 2 \mathrm{H}), 8.54(\mathrm{~d}, 2 \mathrm{H}) ;{ }^{13} \mathrm{C}$ NMR (100 MHz, $\left.\mathrm{CDCl}_{3}\right) \delta 41.80,53.26,60.73,113.22,117.34,122.50,123.54,129.53,136.84$, 149.04, 149.53, 159.66; HRMS (EI): Calcd for $\mathrm{C}_{20} \mathrm{H}_{22} \mathrm{~N}_{4}$ : 318.1844, Found: 318.1846.

4.2.3. $N$-[2-(2,2'-dipicolylamino)ethyl]-p-chloroaniline (2b). $N$-(chlorophenyl)ethylenediamine was prepared in a similar manner to the procedure described above using 2-bromoethylamine hydrobromide $(1.1 \mathrm{~g}, 5.4 \mathrm{mmol})$ and $p$-chloroaniline $(3.4 \mathrm{~g}, 27 \mathrm{mmol})$. Yield: $81 \%(0.75 \mathrm{~g})$ as a brown liquid; ${ }^{1} \mathrm{H}$ NMR (400 MHz, $\mathrm{CDCl}_{3}$ ) $\delta 1.45$ (brs, 3H), 2.95 (t, 2H), 3.15 (t, 2H), 6.55 (d, 2H), 7.11 (d, 2H). Compound $\mathbf{2 b}$ was prepared using 2-(chloromethyl)pyridine hydrochloride (1.5 g, 9.2 mmol), $N$-(4-chlorophenyl)ethylenediamine $(0.75 \mathrm{~g}, 4.5 \mathrm{mmol})$ and triethylamine $(4.5 \mathrm{~g}, 45 \mathrm{mmol})$ in a similar manner to that described above by heating for $3 \mathrm{~h}$ at $80{ }^{\circ} \mathrm{C}$. Yield : $43 \%(0.69 \mathrm{~g})$ as a brown viscous liquid; $\mathrm{mp} 86-88{ }^{\circ} \mathrm{C} ;{ }^{1} \mathrm{H}$ NMR (400 MHz, $\left.\mathrm{CDCl}_{3}\right) \delta 2.87(\mathrm{t}, 2 \mathrm{H}), 3.15(\mathrm{t}, 2 \mathrm{H}), 3.88$ (s, $4 \mathrm{H}), 6.49$ (d, J=8.8Hz, 2H,), 7.07 (d, J=8.8Hz, 2H), 7.11-7.19 (m, 2H), $7.38(\mathrm{~d}, 2 \mathrm{H}), 7.61(\mathrm{t}, 2 \mathrm{H})$, 
$8.55(\mathrm{~d}, 2 \mathrm{H}) ;{ }^{13} \mathrm{C} \mathrm{NMR}\left(100 \mathrm{MHz}, \mathrm{CDCl}_{3}\right) \delta 41.95,53.00,60.72,114.22,121.72,122.54,123.55$, 129.29, 136.83, 147.68, 149.56, 159.55; HRMS (EI): Calcd for $\mathrm{C}_{20} \mathrm{H}_{21} \mathrm{ClN}_{4}$ : 352.1455, Found: 352.1468 .

4.2.4. $\mathrm{N}$-(2-(2,2'-Dipicolylamino)ethyl)-p-anisidine (2c). $N$-(methoxyphenyl)ethylenediamine was prepared in a similar manner to the procedure described above using 2-bromoethylamine hydrobromide (2.0 g, $9.9 \mathrm{mmol})$ and $p$-anisidine $(4.0 \mathrm{~g}, 33 \mathrm{mmol})$. Yield: $88 \%(1.4 \mathrm{~g})$ as a brown solid; ${ }^{1} \mathrm{H}$ NMR (400 MHz, $\left.\mathrm{CDCl}_{3}\right) \delta 1.45$ (br s, 3H), 2.94 (t, 2H), 3.14 (t, 2H), 3.75 (s, 3H), 6.61 (d, 2H), 6.78 (d, 2H). Compound 2c was prepared from 2-(chloromethyl)pyridine hydrochloride (2.1 g, $12 \mathrm{mmol}), \mathrm{N}$-(4-methoxyphenyl)ethylenediamine $(0.79 \mathrm{~g}, 4.7 \mathrm{mmol})$ and triethylamine $(4.5 \mathrm{~g}, 45$ $\mathrm{mmol})$ in a manner similar to that described above by heating for $3 \mathrm{~h}$ at $80{ }^{\circ} \mathrm{C}$. Yield: $26 \%(0.77 \mathrm{~g})$ as a brown viscous solid; mp 37-41 ${ }^{\circ} \mathrm{C} ;{ }^{1} \mathrm{H}$ NMR (400 MHz, $\left.\mathrm{CDCl}_{3}\right) \delta 2.87(\mathrm{t}, 2 \mathrm{H}), 3.14(\mathrm{t}, 2 \mathrm{H})$, $3.73(\mathrm{~s}, 3 \mathrm{H}), 3.88(\mathrm{~s}, 4 \mathrm{H}), 6.55$ (d, J=8.9 Hz, 2H), 6.75 (d, J=8.9 Hz, 2H), 7.11-7.16 (m, 2H), 7.42 $(\mathrm{d}, 2 \mathrm{H}), 7.61(\mathrm{t}, 2 \mathrm{H}), 8.54(\mathrm{~d}, 2 \mathrm{H}) ;{ }^{13} \mathrm{C} \mathrm{NMR}\left(100 \mathrm{MHz}, \mathrm{CDCl}_{3}\right) \delta 42.83,53.45,56.26,60.80$, 114.50, 115.26, 122.45, 123.49, 136.79, 143.40, 149.54, 152.30, 159.73; HRMS (EI): Calcd for $\mathrm{C}_{21} \mathrm{H}_{24} \mathrm{~N}_{4} \mathrm{O}$ : 348.1950, Found: 348.1984; Anal. Calcd for $\mathrm{C}_{21} \mathrm{H}_{24} \mathrm{~N}_{4} \mathrm{O}$ : C 72.39, H 6.94, N 16.08. Found: C 72.04, H 6.79, N 15.89.

4.2.5. p-Bis(2,2'-dipicolylamino)benzene (3a). This compound was prepared from 2-(chloromethyl)pyridine hydrochloride (2.0 g, $12 \mathrm{mmol}), p$-phenylenediamine (0.26 g, $2.4 \mathrm{mmol})$, and triethylamine $(5.8 \mathrm{~g}, 57 \mathrm{mmol})$ in a manner similar to that described above by heating for $2 \mathrm{~h}$ at $80{ }^{\circ} \mathrm{C}$. The crude product was purified by recrystallization from methanol, ethyl acetate and n-hexane to afford a brown crystal. Yield: $48 \%$ (0.55 g); mp 196-197 ${ }^{\circ} \mathrm{C}(\mathrm{dec}) ;{ }^{1} \mathrm{H} \mathrm{NMR}(400 \mathrm{MHz}$, $\left.\mathrm{CDCl}_{3}\right) \delta 4.70(\mathrm{~s}, 8 \mathrm{H}), 6.58(\mathrm{~s}, 4 \mathrm{H}), 7.11-7.15(\mathrm{~m}, 4 \mathrm{H}), 7.29(\mathrm{~d}, 4 \mathrm{H}), 7.58(\mathrm{t}, 4 \mathrm{H}), 8.54(\mathrm{~d}, 4 \mathrm{H}) ;{ }^{13} \mathrm{C}$ NMR $\left(100 \mathrm{MHz}, \mathrm{CDCl}_{3}\right) \delta 58.38,114.73,121.49,122.25,137.06,141.23,149.93,159.95 ;$ HRMS (EI): Calcd for $\mathrm{C}_{30} \mathrm{H}_{28} \mathrm{~N}_{6}$ : 472.2375, Found: 472.2360 .

4.2.6. 2,2'-Dipicolylaminobenzene (3b). This compound was prepared from 2-(chloromethyl)pyridine hydrochloride $(9.5 \mathrm{~g}, 58 \mathrm{mmol})$, aniline $(1.8 \mathrm{~g}, 19 \mathrm{mmol})$ and triethylamine $(5.8 \mathrm{~g}, 57 \mathrm{mmol})$ in a similar manner to that described above by heating for $2 \mathrm{~h}$ at $80{ }^{\circ} \mathrm{C}$. Yield: $55 \%$ (2.9 g) as a brown crystal; mp 111-112 ${ }^{\circ} \mathrm{C} ;{ }^{1} \mathrm{H}$ NMR $\left(400 \mathrm{MHz}, \mathrm{CDCl}_{3}\right) \delta 4.83$ (s, 4H), 6.67-6.75 (m, 3H), 7.11-7.21 (m, 4H), $7.27(\mathrm{~d}, 4 \mathrm{H}), 7.61(\mathrm{t}, 4 \mathrm{H}), 8.59(\mathrm{~d}, 2 \mathrm{H}) ;{ }^{13} \mathrm{C}$ NMR $\left(100 \mathrm{MHz}, \mathrm{CDCl}_{3}\right) \delta 57.73,112.94,117.62,121.22,122.41,129.70,137.20,148.63,150.13$, 159.28; HRMS (EI): Calcd for $\mathrm{C}_{18} \mathrm{H}_{17} \mathrm{~N}_{3}$ : 275.1422, Found: 275.1401; Anal. Calcd for $\mathrm{C}_{18} \mathrm{H}_{17} \mathrm{~N}_{3}$ : C 78.52, H 6.22, N 15.26. Found: C 78.44, H 6.19, N 15.37. 
4.2.7. $p$-(N,N-Dimethylamino)- 2,2'-dipicolylaminobenzene $(3 \mathrm{c})$. This compound was prepared from 2-(chloromethyl)pyridine hydrochloride (3.6 g, $22 \mathrm{mmol}), N, N$-dimethyl- $p$-phenylenediamine $(1.0 \mathrm{~g}, 7.4 \mathrm{mmol})$ and triethylamine $(2.3 \mathrm{~g}, 22 \mathrm{mmol})$ in a similar manner to that described above by heating for $2 \mathrm{~h}$ at $80{ }^{\circ} \mathrm{C}$. Yield: $14 \%(0.34 \mathrm{~g})$ as a brownish crystal; mp 98-100 ${ }^{\circ} \mathrm{C} ;{ }^{1} \mathrm{H}$ NMR $(400$ $\mathrm{MHz}_{\mathrm{CDCl}}$ ): $\delta 2.80(\mathrm{~s}, 6 \mathrm{H}), 4.75(\mathrm{~s}, 4 \mathrm{H}), 6.69(\mathrm{~m}, 4 \mathrm{H}), 7.14(\mathrm{~m}, 2 \mathrm{H}), 7.31(\mathrm{~d}, 2 \mathrm{H}), 7.60(\mathrm{~d}, 2 \mathrm{H})$, $8.57(\mathrm{~m}, 2 \mathrm{H}) ;{ }^{13} \mathrm{C} \mathrm{NMR}\left(100 \mathrm{MHz}, \mathrm{CDCl}_{3}\right) \delta 42.31,58.47,114.72,115.83,121.52,122.26,137.09$, 141.25, 144.12, 149.93, 160.00; HRMS (EI): Calcd for $\mathrm{C}_{20} \mathrm{H}_{22} \mathrm{~N}_{4}$ : 318.1844 , Found: 318.1868 .

4.2.8. 2,2'-Dipicolylaminomethylbenzene (4). This compound was prepared from 2-(chloromethyl)pyridine hydrochloride $(3.7 \mathrm{~g}, 22 \mathrm{mmol})$, benzylamine $(1.0 \mathrm{~g}, 9.3 \mathrm{mmol})$ and triethylamine $(4.7 \mathrm{~g}, 47 \mathrm{mmol})$ in a similar manner to that described above by heating for $4 \mathrm{~h}$ at $80{ }^{\circ} \mathrm{C}$. The crude product was purified by column chromatography on silica gel (eluant: $n$-hexane/ethyl acetate $=2 / 1(\mathrm{v} / \mathrm{v}))$ to afford a yellow viscous liquid. yield: $54 \%(1.5 \mathrm{~g}) ;{ }^{1} \mathrm{H}$ NMR $\left(400 \mathrm{MHz}, \mathrm{CDCl}_{3}\right) \delta 3.69(\mathrm{~s}, 2 \mathrm{H}), 3.81(\mathrm{~s}, 4 \mathrm{H}), 7.10-7.17(\mathrm{~m}, 2 \mathrm{H}), 7.23$ (t, J= 7.4 Hz, 2H,), 7.31 (t, $J=7.4 \mathrm{~Hz}, 2 \mathrm{H},), 7.42(\mathrm{~d}, J=7.0 \mathrm{~Hz}, 2 \mathrm{H}),, 7.59(\mathrm{dt}, 2 \mathrm{H}), 7.66(\mathrm{t}, 2 \mathrm{H}), 8.52(\mathrm{~d}, 2 \mathrm{H}) ;{ }^{13} \mathrm{C} \mathrm{NMR}$ $\left(100 \mathrm{MHz}, \mathrm{CDCl}_{3}\right) \delta 58.94,60.41,122.33,123.16,127.45,128.71,129.25,136.81,139.39,149.37$, 160.23; HRMS (EI): Calcd for $\mathrm{C}_{19} \mathrm{H}_{19} \mathrm{~N}_{3}$ : 289.1579, Found: 289.1582.

\section{Acnowledgements}

This work was supported by a Grant-in-Aid (19550137) and the Global COE from the Ministry of Education, Culture, Sports, Science and Technology of Japan.

\section{References and notes}

1. (a) Weeks, I.; Cmapbell, A. K.; Woodhead, J. S. Clin. Chem. 1983, 29, 1480-1483; (b) Matthews, J. A.; Batki, A.; Hynds, C.; Kricka, L. J. Anal. Biochem. 1985, 151, 205-209.

2. (a) Rauhut, M. M. Acc. Chem. Res. 1969, 2, 80-87; (b) Bos, R.; Tonkin, S. A.; Hanson, G. R.; Hindson, C. M.; Lim, K. F.; Barnett, N. W. J. Am. Chem. Soc. 2009, 131, 2770-2771; (c) Bos, R.; Barnett, N. W.; Dyson, G. A.; Lim, K. F.; Russell, R. A.; Watson, S. P. Anal. Chim. Acta 2004, 502, 141-147; (d) Silava, S. M.; Casallanovo Jr., F.; Oyamaguchi, K. H.; Ciscato, L. F. L. M.; Stevani, C. V.; Baader, W. J. Lumin. 2002, 17, 313-320; (e) Silva, S. M.; Wagner, K.; Weiss, D.; Beckert, R.; Stevani, C. V.; Baader, W. J. Lumin. 2002, 17, 362-369; (f) Stevani, C. V.; Baader, W. J. J. Chem. Res. (S) 2002, 430-432; (g) Milofski, R. E.; Birks, J. W. J. Am. Chem. Soc. 1991, 113, 9715-9723; (h) Hadd, A. G.; Seeber, A.; Birks, J. W. J. Org, Chem. 2000, 65, 2675-2683; (i) Lee, 
J. H.; Rock, J. C.; Park, S. B.; Schlautmann, M. A.; Carraway, E. R. J. Chem Soc. Perkin Trans. 2, 2002, 802-809; (j) Lee, J. H.; Rock, J. C.; Schlautman, M. A.; Carraway, E. R. J. Chem. Soc. Perkin Trans. 2, 2002, 1653-1657; (k) Koike, R.; Motoyoshiya J.; Takaguchi, Y.; Aoyama, H. Chem. Commun. 2003, 794-795; (1) Motoyoshiya, J.; Sakai, N.; Imiai, M.; Yamaguchi, Y.; Koike, R.; Takaguchi, Y.; Aoyama, H. J. Org. Chem. 2002, 67, 7314-7318.

3. (a) Tsunoda, M; Imai, K. Anal. Chim. Acta 2005, 541, 13-23; (b) Gooijer, C.; van Zoonen, P.; Velthorst, N. H.; Frei, R. W. J. Chemilumin. Biolumin. 1989, 4, 479-483.

4. (a) Ciscato, L. F. M. L.; Bartoloni, F. H.; Bastos, E. L.; Baader, W. J. J. Org. Chem. 2009, 74, 8974-8979; (b) Stevani, C. V.; Silva, S. M.; Baader, W. J. Eur. J. Org. Chem. 2000, 4037-4046.

5. Wiskur, S. L.; Ait-Haddou, H.; Lavigne, J. J.; Anslyn, A. V. Acc. Chem. Res. 2001, 34, 963-972.

6. (a) de Silva, A. P.; de Silva, S. A. J. Chem. Soc. Chem. Commun. 1986, 1709-1710; (b) Bissel, R. A.; Calle, E.; de Silva, A. P.; Gunaratne, H. Q. N.; Habib-Jiwan, J. -L.; Peiris, S. L. A.; Rupasinghe, R. A. D. D.; Samarasinghe, T. K. S. D.; Sandanayake, K. R. A. S.; Psoumillion, J. J. Chem. Soc., Perkin Trans. 2 1992, 1559-1564; (c) Gawley, R. E.; Zhang, Q.; Higgs, P. I.; Wang, S.; Leblanc, R. M. Tetrahedron Lett. 1999, 40, 5461-5465.

7. (a) Löhr, H. -G.; Vögtle, F. Acc. Chem. Res. 1985, 18, 65-72. (b) Wickstøm, T.; Dale, J.; Lund, W.; Buøen, S. Anal. Chim. Acta 1988, 211, 223-229; (c) Okamoto, H.; Owari, M.; Kimura, M.; Satake, K. Tetrahedron Lett. 2001, 42, 7454-7455.

8. (a) de Silva, A. P.; Gunaratne, H. Q. N.; Gunnlaugsson, T.; Huxlkey, A. J. M.; McCoy, C. P.; Rademacher, J. T.; Rice, T. E. Chem. Rev. 1997, 97, 1515-1566; (b) Gokel, G. W.; Leevy, W. M.; Weber, M. E. Chem Rev. 2004, 104, 2723-2750; (c) Taki, M.; Iyoshi, S; Ojida, A.; Hamachi I.; Yamamoto, Y. J. Am. Chem. Soc. 2010, 132, 5938-5939; (d) Kobayashi, T.; Urano Y.; Kamiya, M.; Ueno, T.; Kojima, H.; Nagano, T. J. Am. Chem. Soc. 2007, 129, 6696-6697.

9. Wong, Y.-K.; Mak, C.- Y.; Kwan, H. S.; Lee, H. K. Inorg. Chim. Acta 2010, 363, 1246-1253.

10. (a) Rauhut, M. M.; Roberts, B. G.; Semsel, A. M. J. Am. Chem. Soc. 1966, 88, 3604-3617; (b) Catherall, C. L. R.; Palmer, T. F. J. Chem. Soc. Faraday Trans. 2 1984, 80, 837-849.

11. (a) Lee, J. H.; Je, J.; Tartaglia, A.; Hur, J.; Schlautman, M.; Carraway, E. R. J. Photochem. Photobiol. A 2006, 182, 28-32; (b) Shamsipur, M.; Zargoosh, K.; Hosseini, S. M.; Caltagirone, C.; Lippolis, V. Spectrchim. Acta A 2009, 74, 205-209.

12. (a) Weller, A.; Zachariasse, K. Molecular Luminescence, E. C. Lim, Ed. W. A. Bnenjamin, New York, 1969. (b) Adam, W.; Cadilla, C.; Cueto, O.; Rodoriguez, L. O. J. Am. Chem. Soc. 1980, $102,4802-4805$.

13. (a) Romary, J. K.; Barger, J. D.; Bunds J. E. Inorg. Chem. 1968, 7, 1142-1145; (b) H. Tamamura, H.; Ojida, A.; Ogawa, T.; Tsutsumi, H.; Masuno, H.; Nakashima, H.; Yamamoto, N.; Hamachi, I.; Fujii, N. J. Med. Chem. 2006, 49, 3412-3415. 
14. (a) Hirano, T.; Kikuchi, K.; Urano, Y.; Nagano, T. J. Am. Chem. 2002, 124, 6555-6562; (b) Ojida, A.; Sakamoto, T.; Inoue, M.; S. Fijishima, S.; Lippens G.; Hamachi, I. J. Am. Chem. Soc. 2009, 131, 6543-6548.

Graphical Abstract:
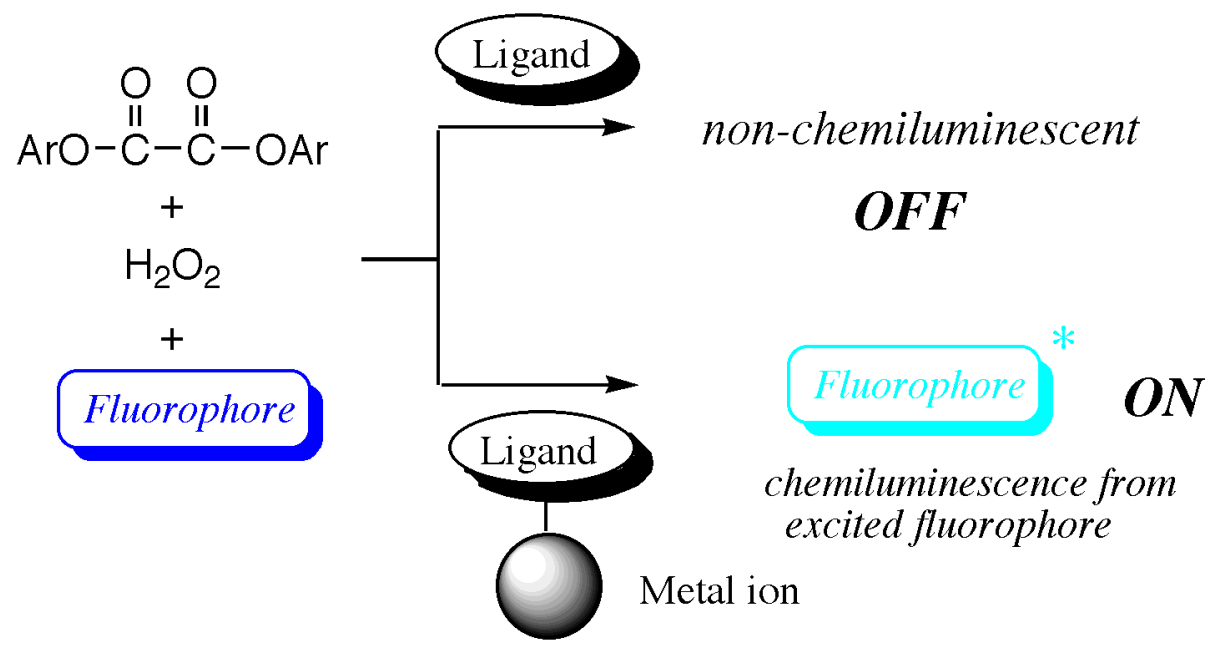